\title{
ANATOMIA DA MADEIRA DE SALIX HUMBOLDTIANA WILLD. (SALICACEAE) ${ }^{1}$
}

\author{
LUCIANO DENARDI ${ }^{2}$ JOSÉ NEWTON CARDOSO MARCHIORI ${ }^{3}$ SIDINEI RODRIGUES DOS SANTOS $^{4}$
}

\section{RESUMO}

É descrita a anatomia da madeira do caule jovem de Salix humboldtiana Willd., com vistas à utilização da espécie em Bioengenharia. Foram observados vasos de pequeno diâmetro $(<85 \mu \mathrm{m})$ e em distribuição semidifusa, parênquima axial marginal, raios heterogêneos exclusivamente unisseriados e abundante fibras gelatinosas.

\section{ABSTRACT}

[Wood anatomy of Salix humboldtiana Willd. (Salicaceae)]

The wood anatomy of Salix humboldtiana Willd. is described, based on young stems, used in Bioengeneering. The anatomical structure shows a semi-diffuse porous wood, small diameter vessels $(<85 \mu \mathrm{m})$, marginal axial parenchyma, heterogeneous and only uniseriate rays, and abundant gelatinous fibres.

\section{INTRODUÇÃO}

Composta, até recentemente, apenas pelos gêneros Salix e Populus, as Salicaceae incorporaram outros gêneros, antes incluídos na família Flacourtiaceae, tais como: Azara, Banara, Casearia e Xylosma (Souza \& Lorenzi, 2005). De acordo com os mesmos autores, a família compreende árvores ou arbustos, raramente lianas, por vezes com espinhos. De distribuição cosmopolita, inclui, atualmente, cerca de 50 gêneros e 1.000 espécies. No Brasil, os gêneros são em número de10, com cerca de 80 espécies.

Salix humboldtiana Willd. é árvore de porte médio $(14-20 \mathrm{~m})$ e tronco reto, inclinado ou tortuoso, de até $90 \mathrm{~cm}$ de diâmetro, e ampla copa de ramificação ascendente. Sua área de ocor- rência estende-se do México até a Argentina e Chile (FAO, 1980; Marchiori, 2000). Habita, usualmente, a margem de cursos de água, sendo freqüente nas bacias dos rios Paraná e Uruguai, inclusive no delta do Prata (Reitz et al., 1988). O salseiro - como é popularmente conhecido -, é uma das árvores mais características e a de maior porte na mata ciliar, ocorrendo em praticamente todo o Rio Grande do Sul (Marchiori, 2000).

Juntamente com Phyllanthus sellowianus Müll. Arg., Sebastiania schottiana (Müll. Arg.) Müll. Arg. e Salix x rubens Shrank, Salix humboldtiana vem recebendo especial atenção no Rio Grande do Sul para o uso em Bioengenharia, com vistas à proteção de taludes flu-

Artigo recebido em 24/04/2007 e aceito para publicação em 05/05/2007.

2 Engenheiro Florestal, bolsista do CNPq-Brasil, doutorando do Programa de Pós-Graduação em Engenharia Florestal, Universidade Federal de Santa Maria, CEP 97105-900, Santa Maria (RS). lucianodenardi@yahoo.com.br

3 Engenheiro Florestal, Dr., bolsista de Produtividade em Pesquisa do CNPq-Brasil, Professor Titular do Departamento de Ciências Florestais, Universidade Federal de Santa Maria, CEP 97105-900, Santa Maria (RS). balduinia@mail.ufsm.br

4 Biólogo, bolsista da CAPES, mestrando do Programa de Pós-Graduação em Engenharia Florestal, Universidade Federal de Santa Maria, CEP 97105-900, Santa Maria (RS). sthurt.bio@gmail.com 
viais (Sutili, 2004; Durlo \& Sutili, 2005; Denardi, 2007).

A estrutura anatômica da madeira de Salix humboldtiana, descrita por Wiedenbrug (1948) e Tortorelli (1956), reúne, entre outros aspectos: porosidade difusa; vasos solitários ou em múltiplos de $2-3$, pequenos $(35-50-110 \mu \mathrm{m}) \mathrm{e}$ numerosos ( 35 a $50 / \mathrm{mm}^{2}$ ); elementos vasculares de $80-430 \mu \mathrm{m}$ de comprimento, com placas de perfuração simples, oblíquas e apêndices ocasionais; pontoações intervasculares alternas e hexagonais, com abertura lenticular inclusa; parênquima apotraqueal marginal (terminal), em faixas de $1-3$ células de espessura, pouco visíveis, mesmo ao microscópio; raios com freqüência de $7-10 / \mathrm{mm}$, heterogêneos e principalmente unisseriados (raros bisseriados), com altura máxima de $500 \mu \mathrm{m}$ e cerca de $18 \mu \mathrm{m}$ de largura; fibras de seção poligonal, por vezes septadas, de 1.000 até $1.300 \mu \mathrm{m}$ de comprimento e com paredes muito delgadas, providas de pontoações simples. A presença de fibras gelatinosas é referida por Marchiori (2004).

Para os gêneros Salix e Populus, cabe agregar que o lenho é constituído principalmente de fibras $(56-79 \%)$, vasos $(20-33 \%)$, raios e parênquima axial, sendo que estes últimos tecidos somam entre 3 e 10\% (FAO, 1980).

\section{MATERIAL E MÉTODOS}

O material em estudo foi coletado na localidade de Passo do Verde (Santa Maria - RS). As exsicatas e a amostra de madeira foram anexadas no Herbário e Xiloteca do Departamento de Ciências Florestais da Universidade de Santa Maria (HDCF), sob o número 5590.

Da amostra de madeira, extraída do caule de um indivíduo de $7 \mathrm{~cm}$ de diâmetro (à altura do peito), foram confeccionados três corpos-deprova, orientados para a obtenção de cortes nos planos transversal, longitudinal radial e longitudinal tangencial. No preparo de lâminas histológicas, seguiu-se a técnica padrão: após fervura em água, os corpos-de-prova foram seccionados em micrótomo de deslize, coloridos com acridina- vermelha, crisoidina e azul-de-astra (Dujardin, 1964), desidratados em série alcoólica crescente e diafanizados com xilol. Em seguida, montaram-se lâminas permanentes contendo os três planos anatômicos, usando-se "Entellan" como meio de montagem.

Para a dissociação do tecido lenhoso, usouse o método de Jeffrey (Burger \& Richter, 1991): solução aquosa de ácido nítrico e ácido crômico, ambos a $10 \%$, na proporção $1: 1$, em dois banhos sucessivos. Concluída a maceração, as células foram reunidas em funil com papel de filtro, onde foram tingidas com solução de safranina $1 \%$. As etapas de desidratação, diafanização e montagem de lâminas permanentes seguiram as mesmas orientações adotadas no preparo de lâminas histológicas, com a diferença de que as duas primeiras etapas foram desenvolvidas sobre papel de filtro.

A descrição microscópica baseou-se nas normas do IAWA Committee (1989). Para a determinação da fração de tecidos, seguiu-se a metodologia proposta por Marchiori (1980). O registro fotográfico foi feito em microscópio Olympus CX-40, equipado com câmara digital.

\section{DESCRIÇÃO MICROSCÓPICA}

Aspectos gerais: lenho composto principalmente por fibras (62\%); destas, cerca de $30 \%$ são gelatinosas. Os vasos correspondem a $23 \%$, os raios somam $13 \%$ e o parênquima axial, a $2 \%$ do volume da madeira. Anéis de crescimento demarcados por estreita camada de fibras achatadas radialmente, por parênquima marginal e pelos poros ligeiramente maiores, no começo do lenho inicial (Figura 1A, B).

Parênquima axial: marginal, disposto em séries de 2-3 células, formando faixas mais ou menos contínuas no limite do anel de crescimento. Inclusões minerais, ausentes no ma e

Vasos: em distribuição semi-difusa, solitários ou dispostos em múltiplos radiais de 2 - 3 (Figura 1A), com freqüência de $94 \pm 32$ (50$150)^{*}$ vasos $/ \mathrm{mm}^{2}$. Poros de seção poligonal, de $64 \pm 10(41-85) \mu \mathrm{m}$ de diâmetro, com paredes 

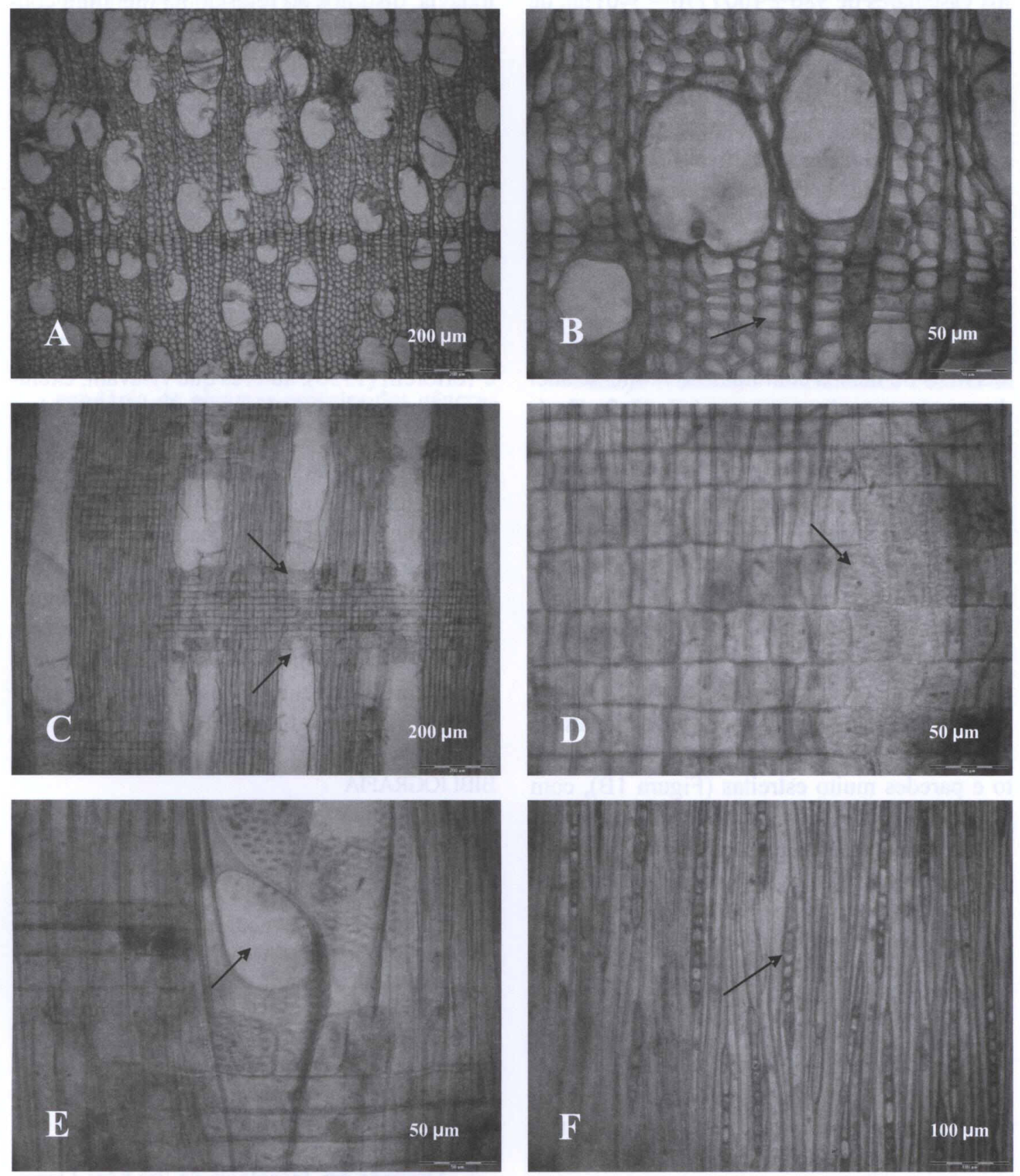

FIGURA 1 - Seção transversal, destacando a porosidade semi-difusa, vasos solitários ou em múltiplos radiais e limite de anel de crescimento (A). Fibras de paredes muito estreitas (seta), em seção transversal (B). Seção longitudinal radial, destacando pontoações raio-vasculares (seta) nas extremidades dos raios (C). Raio heterogêneo e pontoações raiovasculares aparentemente simples (seta), em seção longitudinal radial (D). Placa de perfuração simples (seta), em seção longitudinal radial (E). Raios exclusivamente unisseriados (seta), em seção longitudinal tangencial (F). 
de $2,2 \pm 1(1,2-7,8) \mu \mathrm{m}$ de espessura. Elementos vasculares de $386 \pm 100(170-540) \mu \mathrm{m}$ de comprimento, providos de apêndices e placas de perfuração simples (Figura 1E), oblíquas. Espessamentos helicoidais, tiloses e depósitos, ausentes. Pontoações intervasculares alternas, poligonais, de $6,0-7,7 \mu \mathrm{m}$ de diâmetro, com aberturas elípticas. Pontoações raio-vasculares aparentemente simples e poligonais, com bordas reduzidas (Figura 1D); medem 4,6-6,8 $\mu \mathrm{m}$ de diâmetro e ocorrem, sobretudo, nas extremidades dos raios (Figura 1C).

Parênquima axial: marginal, formando faixas mais ou menos contínuas no limite de anel de crescimento, disposto em séries de $2-3$ células. Inclusões minerais, ausentes no material estudado.

Raios: com freqüência de $16 / \mathrm{mm}$, exclusivamente unisseriados (Figura $1 \mathrm{~F}$ ) e heterogêneos (Figura 1D), reunindo células procumbentes, quadradas e eretas; medem $219 \pm 80$ (75427) $\mu \mathrm{m}$ de altura por $13 \pm 2(8-16) \mu \mathrm{m}$ de largura. Canais intercelulares, tubos lactíferos e inclusões minerais, ausentes.

Fibras: não-septadas, por vezes gelatinosas, de $643 \pm 87(480-840) \mu \mathrm{m}$ de comprimento e paredes muito estreitas (Figura 1B), com pontoações simples de abertura circular. Traqueídeos vasculares, traqueídeos vasicêntricos e espessamentos helicoidais, ausentes.

* $\mathrm{x} \pm \mathrm{s}$ (valor mínimo - valor máximo), onde: $\mathrm{x}=$ média; $\mathrm{s}=$ desvio padrão.

\section{ANÁLISE DA ESTRUTURA ANATÔMICA}

Com relação à composição do tecido lenhoso de Salix humboldtiana, os valores encontrados estão plenamente de acordo com o referido, pela FAO (1980), para os gêneros Salix e Populus.

A presente descrição anatômica concorda, em linhas gerais, com aquela feita por Wiedenbrug (1948) e Tortorelli (1956); a freqüência de vasos e raios, bem como o compri- mento de fibras e a porosidade, mostraram-se, todavia, distintos do referido na literatura consultada. Tais diferenças, podem ser atribuídas principalmente a dois fatores: a diferenças de ambiente, na coleta de material, posto que a anatomia da madeira costuma variar segundo as condições ambientais, fato exaustivamente referido em trabalhos de anatomia ecológica (Baas, 1973; Barajas-Morales, 1985; Lindorf, 1994; Denardi, 2004); e ao fato da amostra de madeira estudada ser de lenho juvenil (tendo-se em vista o porte reduzido do indivíduo coletado), diferentemente do utilizado por Wiedenbrug (1948) e Tortorelli (1956), autores que visavam, exclusivamente, à descrição anatômica da espécie.

A presença abundante de fibras gelatinosas no lenho de Salix humboldtiana, igualmente constatada por Marchiori (2004), confere, ao que tudo indica, maior flexibilidade ao caule. Este aspecto é particularmente importante em indivíduos que habitam margens de cursos d'água, pois aumenta sua capacidade de curvar-se, sem quebrar; esta flexibilidade é especialmente vantajosa em Bioengenharia, na proteção de taludes fluviais (Denardi, 2007).

\section{BIBLIOGRAFIA}

Baas, P. The wood anatomical range in Ilex (Aquifoliaceae) and its ecological and phylogenetic significance. BLUMEA, v. 21, p. 193-258, 1973.

Barajas-Morales, J. Wood structural differences between trees of two tropical forests in Mexico. IAWA Bull., v. 6, n. 4, p. 355-364, 1985.

Burger, L. M., Richter, H. G. Anatomia da madeira. São Paulo: Ed. Nobel, 1991. 154p.

Denardi, L. Estudo anatômico do lenho e morfologia foliar de Blepharocalyx salicifolius (H.B.K.) Berg, em duas regiões do Rio Grande do Sul. Santa Maria: UFSM, 2004. 94f. Dissertação (Mestrado em Tecnologia de Produtos Florestais) - Universidade Federal de Santa Maria.

Denardi, L. Anatomia e flexibilidade do caule de quatro espécies lenhosas para o manejo biotécnico de cursos de água. Santa Maria: UFSM, 2007. 113p. Tese (Doutorado em Manejo Florestal) Universidade Federal de Santa Maria. 
Dujardin, E. P. Eine neue Holz-Zellulosenfaerbung. Mikrokosmos, n.53, p.94, 1964.

Durlo, M. A., Sutili, F. J. Bioengenharia: Manejo biotécnico de cursos de água. Porto Alegre: EST, 2005. 189p.

FAO. Los álamos y los sauces en la producción de madera y la utilización de las tierras. Roma: FAO. 1980.

IAWA Committee. IAWA list of microscopic features for hardwood identificacion. IAWA Bull., v. 10, n. 3, p. 218-359, 1989.

Lindorf, H. Eco-anatomical wood features of species from a very dry tropical Forest. IAWA Journal, v. 15, n. 4, p. 361-376, 1994.

Marchiori, J. N. C. Estudo anatômico do xilema secundário de algumas espécies dos gêneros Acacia e Mimosa, nativas no estado do Rio Grande do Sul. Curitiba: UFPR, 1980. 186f. Dissertação (Mestrado em Engenharia Florestal) - Universidade Federal do Paraná.
Marchiori, J. N. C. Dendrologia das Angiospermas: das Bixáceas às Rosáceas. Santa Maria: Ed. UFSM, 2000.240p.

Marchiori, J. N. C. Fitogeografia do Rio Grande do Sul: Campos sulinos. Porto Alegre: EST, 2004. 110p.

Reitz, R, Klein, R. M., Reis, A. Projeto madeira do Rio Grande do Sul. PortoAlegre: Sudesul, 1988. 525p.

Souza, V. C., Lorenzi, H. Botânica sistemática: guia ilustrado para identificação das famílias de Angiospermas Dicotiledôneas da flora brasileira, baseado em APG II. Nova Odessa: Instituto Plantarum, 2005. 640p.

Sutili, F. J. Manejo biotécnico do arroio Guarda-mor: princípios, processos e práticas. Santa Maria: UFSM, 2004. 114f. Dissertação (Mestrado em Manejo Florestal) - Universidade Federal de Santa Maria.

Tortorelli, L. A. Maderas y bosques argentinos. Buenos Aires: ACME, 1956. 910p.

Wiedenbrug, W. Maderas chilenas: contribuição a su anatomia e identificacion. Lilloa, n. 16, 1948. 